This is an electronic reprint of the original article. This reprint may differ from the original in pagination and typographic detail.

Author(s): Ly, Hanh; Moilanen, Jani; Tuononen, Heikki; Parvez, Masood; Roesler, Roland

Title: $\quad$ More electron rich than cyclopentadienyl: 1,2-diaza-3,5-diborolyl as a ligand in ferrocene and ruthenocene analogs

Year: $\quad 2011$

Version:

Please cite the original version:

Ly, H., Moilanen, J., Tuononen, H., Parvez, M., \& Roesler, R. (2011). More electron rich than cyclopentadienyl: 1,2-diaza-3,5-diborolyl as a ligand in ferrocene and ruthenocene analogs. Chemical Communications, 47(29), 8391-8393. https://doi.org/10.1039/C1CC12281A

All material supplied via JYX is protected by copyright and other intellectual property rights, and duplication or sale of all or part of any of the repository collections is not permitted, except that material may be duplicated by you for your research use or educational purposes in electronic or print form. You must obtain permission for any other use. Electronic or print copies may not be offered, whether for sale or otherwise to anyone who is not an authorised user. 


\title{
More Electron Rich than Cyclopentadienyl: 1,2-Diaza-3,5-diborolyl as a Ligand in Ferrocene and Ruthenocene Analogs
}

\author{
Hanh V. Ly, Jani Moilanen, ${ }^{\mathrm{b}}$ Heikki M. Tuononen, ${ }^{\mathrm{b}}$ Masood Parvez, ${ }^{\mathrm{a}}$ and Roland Roesler*,a
}

Ruthenium and iron sandwich complexes incorporating cyclopentadienly analogs with $\mathrm{CB}_{2} \mathrm{~N}_{2}{ }^{-}$skeletons were characterized. Electrochemical measurements supported by 10 computational studies revealed that in combination with larger metal ions such as $\mathrm{Ru}$ the $\mathrm{CB}_{2} \mathrm{~N}_{2}^{-}$ligand can be more electronrich than its organic counterpart.

The search for heterocyclic cyclopentadienyl analogs was motivated by the exceptional coordinative properties and 15 numerous applications of the parent compound in organometallic chemistry and catalysis. ${ }^{1}$ The incorporation of heteroelements in the ring skeleton aimed to tune the electronic properties of the $\pi$-ligand and expand the knowledge of main group elements. In the decades following 20 the discovery and elucidation of the bonding in ferrocene, ${ }^{2}$ metal complexes featuring five-membered heterocyclic $\mathrm{Cp}$ analogs containing various main group elements were reported. ${ }^{3}$ The majority of these ligands contain only one heteroelement in the ring skeleton. Notable exceptions include 25 ligands containing up to five substituent-free group 15 elements in the ring framework, which display a rich coordination chemistry. ${ }^{4}$ Most boron-containing $\mathrm{Cp}$ analogs include the $\mathrm{B}, \mathrm{N},{ }^{5 \mathrm{a}} \mathrm{B}, \mathrm{S}^{5 \mathrm{~b}, \mathrm{c}}$ or $\mathrm{B}, \mathrm{O}^{5 \mathrm{~d}}$ pairs that are isolobal with the $\mathrm{C}_{2}$ fragment. A cyclopentadienyl analog with a $\mathrm{GeSi}_{2} \mathrm{C}_{2}^{-}$ 30 framework, stabilized in a ferrocene-type complex, remains so far the only ligand in this category containing more than one heavier group 14 element. $^{6}$

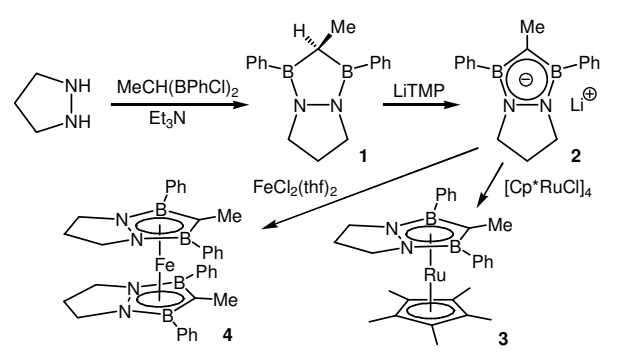

35 Scheme 1 Synthesis of derivatives $1-4$.

A truly "inorganic" ferrocene containing no carbon atoms in the ligand skeleton is still unknown, and early claims regarding the synthesis of a ferrocene featuring $\mathrm{B}_{2} \mathrm{~N}_{3}{ }^{-}$ligands have not yet been substantiated by a crystal structure. ${ }^{7}$ The 40 closest analogs to an "inorganic" ferrocene are compounds featuring phosphorus ligands, such as $\left[\mathrm{Cp} * \mathrm{Fe}\left(\eta^{5}-\mathrm{P}_{5}\right)\right],{ }^{4,8 \mathrm{a}}$ and the fully inorganic titanocene $\left[\mathrm{Ti}\left(\eta^{5}-\mathrm{P}_{5}\right)_{2}\right]^{2-} .{ }^{8 b} \mathrm{In}$ fact, prior to our work, the only reported complexes from this class that contained ligands featuring more than three heteroelements in 45 the ring skeleton have been pnictogen derivatives.

The formal replacement of $\mathrm{C}_{2}$ fragments with isoelectronic $\mathrm{BN}$ moieties in simple organic entities has received considerable interest recently, resulting in the isolation of several remarkable molecules with exquisite properties. ${ }_{50}$ Analogs of pyrene, ${ }^{9 \mathrm{a}}$ benzene, ${ }^{9 \mathrm{~b}}$ ethyl, ${ }^{9 \mathrm{c}}$ ethylene, ${ }^{9 \mathrm{~d}, \mathrm{e}}$ and propane $^{9 \mathrm{f}}$ incorporating the $\mathrm{BN}$ fragment have been characterized, free or stabilized in the coordination sphere of transition metals. In this context, we reported a family of ligands with $\mathrm{CB}_{2} \mathrm{~N}_{2}{ }^{-}$frameworks and characterized their 55 complexes with group 1 and 12 metals. ${ }^{10}$ The coordination chemistry of these ligands was similar to that of $\mathrm{Cp}$, although substantial differences were observed as well. The ring carbon atom proved to play a central role in the binding of the ligand to metals and only $\eta^{1}, \eta^{2}, \eta^{3}$ and $\eta^{4}$-coordination modes were 60 observed, with the ring nitrogen atoms displaying considerable pyramidalization (CNNC torsion angles of 17 $44^{\circ}$ ). Reported herein are the first transition metal sandwich compounds employing ligands with $\mathrm{CB}_{2} \mathrm{~N}_{2}^{-}$skeletons that display a classical, $\eta^{5}$-coordination of the heterocyclic ring. 65

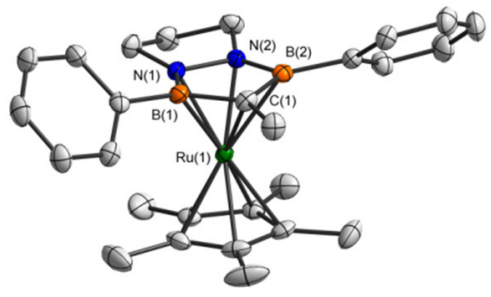

Fig. 1 Molecular structure of 3 with $50 \%$ probability level thermal ellipsoids. Hydrogen atoms have been omitted for clarity. Selected bond lengths (A): B-C(1) 1.511(4), 1.522(4), B-N 1.479(3), 1.487(3), N-N 70 1.431(3), Ru-C(1) 2.296(2), Ru-B 2.322(3), 2.323(3), Ru-N 2.126(2), $2.127(2), \mathrm{Ru}-\mathrm{C}_{\mathrm{Cp} *} 2.154(2)-2.194(2)$.

A new precursor $\mathbf{1}$ featuring a cyclic, pyrazolidyl backbone was synthesized in a fashion similar to reported procedures, ${ }^{10}$ in an attempt to enforce a reduction of the CNNC dihedral 75 angle and hence improve the participation of the nitrogen lone pairs to the $\pi$-system of the ligand. The deprotonation of $\mathbf{1}$ with formation of $\mathbf{2}$ was easily accomplished using LiTMP and the corresponding change in molecular symmetry from $C_{s}$ to $C_{2 v}$ was obvious in the NMR spectra. The reaction of 2 with ${ }_{80}[\mathrm{Cp} * \mathrm{RuCl}]_{4}$ and $\left[\mathrm{FeCl}_{2}(\mathrm{thf})_{2}\right]$ yielded complexes $\mathbf{3}$ and $\mathbf{4}$, respectively, in good yields. The chemical shifts for the heterocyclic ring carbon $(22.4,91.6,80.0$ and $65.5 \mathrm{ppm}$ in $\mathbf{1}$, $\mathbf{2}, \mathbf{3}$ and 4, respectively) mirror the shift of the corresponding carbon resonances in $\mathrm{Cp}^{*}(52.2,105.2,82.9$ and $78.4 \mathrm{ppm}$ in ${ }_{85} \mathrm{Cp}^{*} \mathrm{H}, \mathrm{Cp}{ }^{*} \mathrm{Na}, \mathrm{Cp}^{*}{ }_{2} \mathrm{Ru}$ and $\mathrm{Cp}^{*}{ }_{2} \mathrm{Fe}$, respectively). ${ }^{10 \mathrm{~b}, 11}$ The ${ }^{11} \mathrm{~B}$ resonances $(39.3,31.5,14.7$ and $13.6 \mathrm{ppm}$ in $\mathbf{1}, \mathbf{2}, \mathbf{3}$ and 4, respectively) fall in the range observed for $\mathrm{Ru}(14-18 \mathrm{ppm})$ and $\mathrm{Fe}(3-22 \mathrm{ppm})$ metallocenes incorporating ligands with $\mathrm{C}_{3} \mathrm{BN}^{-}$frameworks. ${ }^{12}$ 


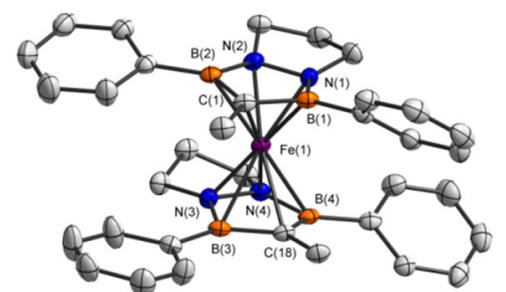

Fig. 2 Molecular structure of 4 with $50 \%$ probability level thermal ellipsoids. Hydrogen atoms have been omitted for clarity. Selected bond lengths $(\AA)$ : B-C(1) and B-C(18) 1.510(4) - 1.521(4), B-N 1.472(3) 5 1.489(4), N-N 1.436(3), 1.439(3), Fe-C(1) and Fe-C(18) 2.177(2), 2.192(2), Fe-B 2.198(3) - 2.217(3), Fe-N 1.971(2) - 1.997(2).

Single crystal X-ray diffraction analysis revealed for both $\mathbf{3}$ (Fig. 1) and 4 (Fig. 2) typical sandwich structures with parallel, $\eta^{5}$-coordinating $\pi$-ligands (Fig. 3). The $\mathrm{CB}_{2} \mathrm{~N}_{2}$ rings 10 are reasonably planar (sum of the intraannular angles 538.8 $539.4^{\circ}$ ) but their geometry is best described as an envelope conformation with a dihedral angle along the $\mathrm{B} \cdots \mathrm{B}$ axis of 8 $11^{\circ}$, which allows for a larger separation between the metal and the larger boron atoms. The CNNC torsion angles were

15 reduced considerably in comparison to other ligands from this family, to only $2-3^{\circ}$. However, the $\mathrm{C}_{2} \mathrm{~N}_{2}$ planes form dihedral angles of $11-15^{\circ}$ with the $\mathrm{B}_{2} \mathrm{~N}_{2}$ planes and hence the nitrogen atoms remain slightly pyramidal. The intraannular $\mathrm{C}-\mathrm{B}$ and $\mathrm{B}-\mathrm{N}$ bonds display distinct multiple 20 bond character, while the N-N distances are typical of single bonds. The distance between the metal and the best plane of the $\mathrm{CB}_{2} \mathrm{~N}_{2}$ ring was $1.67 \AA$ for $\mathrm{Fe}$ and $1.84 \AA$ for $\mathrm{Ru}$, nearly identical to the corresponding distances in $\mathrm{Cp}_{2} \mathrm{M}$ (1.66 $\AA$ for $\mathrm{Fe}$ and $1.84 \AA$ for $\mathrm{Ru})$ and $\mathrm{Cp}{ }_{2} \mathrm{M}(1.66 \AA$ for $\mathrm{Fe}$ and $1.80 \AA$ ${ }_{25}$ for $\left.\mathrm{Ru}\right){ }^{13}$
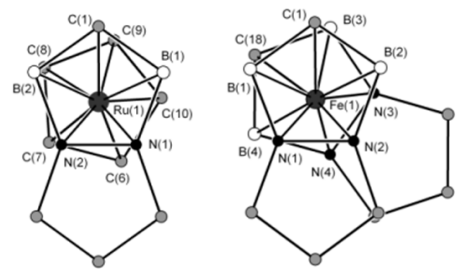

Fig. 3 Perpendicular projection onto the $\mathrm{CB}_{2} \mathrm{~N}_{2}$ planes of 3 (left) and 4 (right) revealing the hapticity of the ligand. Ring substituents have been omitted for clarity.

30 A cyclovoltammetric study showed that both $\mathbf{3}$ and $\mathbf{4}$ display reversible oxidation steps at +0.45 and $-0.04 \mathrm{~V}$, respectively, vs. SCE in $\mathrm{CH}_{2} \mathrm{Cl}_{2}$. The reported values for $\mathrm{Cp}^{*}{ }_{2} \mathrm{Ru}(+0.55 \mathrm{~V}), \mathrm{Cp}_{2} \mathrm{Fe}(+0.46 \mathrm{~V})$, and $\mathrm{Cp}^{*}{ }_{2} \mathrm{Fe}(-0.11 \mathrm{~V})$ indicate that the diazadiborolidine ligands reported herein are 35 comparable to or better electron donors than the parent cyclopentadienyl, ${ }^{14}$ confirming the results of a previous study showing that the presence of a $\mathrm{BN}$ fragment in the cyclopentadienyl framework generates ligands with superior electron donating capability. ${ }^{15}$ However, in the case of $\mathbf{3}$ and $\mathbf{4}$ 40 a direct comparison of the ligand skeletons is hindered by the lack of data for identically substituted ligands. Hence, a computational investigation was carried out for a set of model systems (see Supplementary Information).

Density functional theory was employed to calculate the first

45 ionization energies of $\mathrm{Fe}$ and $\mathrm{Ru}$ sandwich compounds. The results show that the ionization energy of $\mathrm{Cp}^{*}{ }_{2} \mathrm{Fe}$ is $10 \mathrm{~kJ} \mathrm{~mol}$
${ }^{1}$ lower than that of its $\mathrm{CB}_{2} \mathrm{~N}_{2}{ }^{-}$analog, whereas the trend is reversed for $\mathrm{Ru}$ complexes, in which case the difference is also slightly bigger, $16 \mathrm{~kJ} \mathrm{~mol}^{-1}$. In addition, the calculated 50 ionization energies decrease consistently by $c a .10 \mathrm{~kJ} \mathrm{~mol}^{-1}$ if the $\mathrm{CB}_{2} \mathrm{~N}_{2}^{-}$ligand contains a pyrazolidyl backbone. Comparable ionization energies were also calculated for $\mathrm{Fe}$ and $\mathrm{Ru}$ complexes incorporating methylated ligands based on a $\mathrm{C}_{3} \mathrm{BN}^{-}$framework. These data correlate well with the 55 experimental results and confirm the importance of the bicyclic ligand design. They indicate that, for an identical substitution pattern, the larger $\mathrm{CB}_{2} \mathrm{~N}_{2}{ }^{-}$ring (av. intraannular bond length $1.49 \AA$ in 3 ) is a better electron donor than cyclopentadienyl (av. intraannular bond length $1.43 \AA$ in 3) ${ }_{60}$ for the larger $\mathrm{Ru}$ and a poorer electron donor for the smaller $\mathrm{Fe}$, likely due to differences in orbital overlap.

Derivatives 3 and 4 prove that the $\mathrm{BN}$ pair provides a viable platform for the design of heteroatom-rich cyclopentadienyl analogs. Unlike other systems we ${ }_{65}$ investigated, ${ }^{10}$ these efficient ligands display a classical $\eta^{5}$ coordination mode towards $\mathrm{Fe}$ and $\mathrm{Ru}$ and are comparable to or, in the case of the latter metal, even more electron rich than the parent carbon ring, generating complexes with increased reducing ability.

70 This work was supported by the Natural Sciences and Engineering Research Council of Canada, the Canada Foundation for Innovation, the Academy of Finland and the Alberta Science and Research Investments Program.

\section{Notes and references}

$75{ }^{a}$ Department of Chemistry, University of Calgary, 2500 University Drive NW, Calgary, AB, T2N 1N4 Canada. Fax: +1 (403) 289 9488; Tel: +1 (403) 220 5366; E-mail: roesler@ucalgary.ca

${ }^{b}$ Department of Chemistry, University of Jyväskylä, P.O. Box 35, FIN40014 Jyväskylä, Finland. Fax: +358 (14) 260 2501; Tel: +358 (14) 260 80 2618; E-mail:xxxx@aaa.bbb.ccc

1 (a) A. Togni and R. L. Halterman, Metallocenes, Wiley VCH, Weinheim 1998, Vol. I, II; (b) N. Long, J. Metallocenes: An Introduction to Sandwich Complexes, Blackwell Science Ltd., London 1998; (c) P. Jutzi and N. Burford, Chem. Rev. 1999, 99, 969.

2 (a) T. J. Kealy and P. L. Pauson, Nature 1951, 168, 1039; (b) G.Wilkinson, M. Rosenblum, M. C. Whiting and R. B. Woodward, J. Am. Chem. Soc. 1952, 74, 2125; (c) R. B. Woodward, M. Rosenblum and M. C. Whiting, J. Am. Chem. Soc. 1952, 74, 3458; (d) E. O. Fischer and W. Pfab, Z. Naturforsch. 1952, 7B, 377; (e) E. Ruch and E. O. Fischer, Z. Naturforsch. 1952, 7B, 676; (f) P. F. Eiland and R. Pepinsky, J. Am. Chem. Soc. 1952, 74, 4971.

3 See ref. $10 \mathrm{~b}$ for a timeline of the reports on the first $\mathrm{Cp}$ analogs.

4 (a) O. J. Scherer, Angew. Chem., Int. Ed. Engl. 1990, 29, 1104; (b) M. Scheer and E. Herrmann, Z. Chem. 1990, 30, 41; (c) F. Mathey, Coord. Chem. Rev. 1994, 137, 1; (d) J. F. Nixon, Chem. Soc. Rev. 1995, 24, 319; (e) M. Scheer, S. Deng, O. J. Scherer and M. Sierka, Angew. Chem., Int. Ed. 2005, 44, 3755.

5 (a) J. Schulze and G. Schmid, Angew. Chem., Int. Ed. Engl. 1980, 19, 54; (b) A. J. Ashe III, X. Fang and J. W. Kampf, Organometallics 1998, 17, 2379; (c) A. J. Ashe III, J. W.Kampf, M. Schiesher, Organometallics 2000, 19, 4681; (d) J. Chen, X. Fang, Z. Bajko, J. W. Kampf and A. J. Ashe III, Organometallics 2004, 23, 5088.

6 V. Y. Lee, R. Kato, A. Sekiguchi, A. Krapp and G. Frenking, J. Am. Chem. Soc. 2007, 129, 10340.

7 H. Nöth and W. Regnet, Z. Anorg. Allg. Chem. 1967, 352, 1. 
8 (a) O. J. Scherer and T. Brück, Angew. Chem., Int. Ed. Engl. 1987, 26, 59; (b) E. Urnèžius, W. W. Brennessel, C. J. Cramer, J. E. Ellis, P. v. R. Schleyer, Science 2002, 295, 832.

9 (a) M. J. D. Bosdet, W. E. Piers, T. S. Sorensen and M. Parvez, Angew. Chem. Int. Ed. 2007, 46, 4940; (b) A. J. V. Marwitz, M. H. Matus, L. N. Zakharov, D. A. Dixon and S.-Y. Liu, Angew. Chem. Int. Ed. 2009, 48, 973; (c) T. D. Forster, H. M. Tuononen, M. Parvez and R. Roesler, J. Am. Chem. Soc. 2009, 131, 6689; (d) G. Alcaraz, L. Vendier, E. Clot and S. Sabo-Etienne, Angew. Chem. Int. Ed. 2010, 49, 918; (e) C. Y. Tang, A. L. Thompson and S. Aldridge, Angew. Chem. Int. Ed. 2010, 49, 921; (f) S. R. Daly, B. J. Bellott, D. Y. Kim and G. S. Girolami, J. Am. Chem. Soc. 2010, 132, 7254.

10 (a) Ly, H. V.; Forster, T. D.; Maley, D.; Parvez, M.; Roesler, R. Chem. Commun. 2005, 4468-4470. (b) Ly, H. V.; Forster, T. D.; Corrente, A. M.; Eisler, D. J.; Konu, J.; Parvez, M.; Roesler, R. Organometallics 2007, 26, 1750-1756. (c) Ly, H. V.; Forster, T. D.; Parvez, M.; McDonald, R.; Roesler, R. Organometallics 2007, 26 , 3516-3523. (d) Ly, H. V.; Tuononen, H. M.; Parvez, M.; Roesler, R. Angew. Chem., Int. Ed. 2008, 47, 361-364. (e) Ly, H. V.; Konu, J. Parvez, M.; Roesler, R. Dalton Trans. 2008, 3454-3460.

11 (a) Robbins, J. L.; Edelstein, N.; Spencer, B.; Smart, J. C. J. Am Chem. Soc. 1982, 104, 1882-1893. (b) Tilley, T. D.; Grubbs, R. H.; Bercaw, J. E. Organometallics 1984, 3, 274-278.

12 (a) Amirkhalili, S.; Höhner, U.; Schmid, G. Angew. Chem., Int. Ed. Engl. 1982, 21, 68. (b) Schmid, G.; Höhner, U.; Kampmann, D.; Zaika, D.; Boese, R. Chem. Ber. 1983, 116, 951-959. (c) Schmid, G. Haske, S.; Zaika, D.; Boese, R.; Bläser, D. Chem. Ber. 1994, 127, 7380. (f) Schmid, G.; Barbenheim, G.; Boese, R. Z. Naturforsch. 1985 , 40B, 787-793.

13 (a) Dunitz, J. D.; Orgel, L. E.; Rich, A. Acta Cryst. 1956, 9, 373-375.

(b) Hardgrove, G. L.; Templeton, D. H. Acta Cryst. 1959, 12, 28-32.

(c) Freyberg, D. P.; Robbins, J. L.; Raymond, K. N.; Smart, J. C. J. Am. Chem. Soc. 1979, 101, 892-897. (d) Zhang, Y.; Kim, C. D.; Coppens, P. Chem. Commun. 2000, 2299-2300.

14 (a) Astruc, D. Electron Transfer and Radical Processes in TransitionMetal Chemistry, VCH, New York 1995. (b) Connelly, N. G.; Geiger, W. E. Chem. Rev. 1996, 96, 877-910.

15 Liu, S.-Y.; Lo, M. M.-C.; Fu, G. C. Angew. Chem., Int. Ed. 2002, 41, 174-176. 